\title{
Loess forming depth and its' microstructure difference
}

\author{
DENG Jin ${ }^{1, a}$, Li ping ${ }^{2}$
}

1. Lanzhou Institute of Seismology, CEA, Lanzhou 730000, China; Key Laboratory of Loess Earthquake Engineering, CEA, Lanzhou 730000, China; Geotechnical Disaster Prevention Engineering Technology Research Center of Gansu Province, Lanzhou 730000, China (dengjin@gssb.gov.cn)

2. Lanzhou Institute of Seismology, CEA, Lanzhou 730000, China

Keywords: Climate change; Loess microstructure; Sand-dropping size

Abstract. Based on images and indices of loess microstructure in the major sedimentary areas of northwest China, characteristics of loess formed in different sedimentary ages are compared. It bring forward the method of loess forming in different climate period and its microstructure characteristics. According compared, it can be regarded as a new reliable proof of climatic changes.

\section{Introduction}

Loess in Gansu of China is characterized by its great thickness and broad range of coverage[1-2]. The thickest loess stratum is over 400 meters deep, such as the Xijincun loess section in Lanzhou. Since the color segmentation there between Malan loess and paleosol layer is not so distinct, loess in Gansu is usually not considered as good indicator of climate. However, since loess in Gansu is formed in cold and dry areas, close to desert, the aeolian dusts accumulate rapidly. Besides, since cemented clay particles are few, grain shapes and binding modes can be seen clearly with the help of electron microscope. There are few in-depth studies that include the loess micro-structure, but some scholars do believe that it can reflect climate[3-6].

This paper attempts to apply the microstructure to climatic changes. It is the sedimentary characteristics of aeolian loess are the proof of climatic changes in different ages caused by the rapid rise of the Qinghai-Tibetan Plateau. Deep in the inland of China, Lanzhou, together with its surrounding areas, is a part of the temperate semi-arid region and one of the major Malan loess sedimentary areas. Micro-structural characteristics have a profound influence to its engineering properties of loess, and related literature [7-10]. This article attempts to establish the method for microstructure to climatic changes.

\section{Samples and research Method}

Since 1990 years, much has been achieved in the dating studies of the glacial ages and some dating statistics have been obtained (Lu Huayu, et a1, 2004). It is generally believed that Malan loess (L1) was accumulated between 76ka and 12ka, spanning the Lushan Glacial (76-60ka, the interstade (60-30ka, the glacial maximum (Dali Glacial) (LGM, 30-15ka) , the deglaciation (15-12ka) ,the post-glacial (1.0-1.2ka) and the Holocene (1-0.2ka). Since the loess accumulation speed in Lanzhou is about 5-6m/10ka (Chen Fahu, 1998), the following climatic proofs can be found in corresponding loess layers.

\section{Loessial Microstructure in 3-3.5m}

The climate in the Holocene was characterized by warm and humidity, however, there were temperature decreases and glacier advancements around 4-3kaBP. In 3-3.5m of Jingtai loess, the aggregate of cemented clay particles, is shown in the image of the sample from Jingtai at $3.5 \mathrm{~m}$ in Fig. 
1. It's particle sizes(3694-4765) is small and fine. Indicates it might have been formed in a humid climate. It can prove the climate in the Holocene was warm and humid,

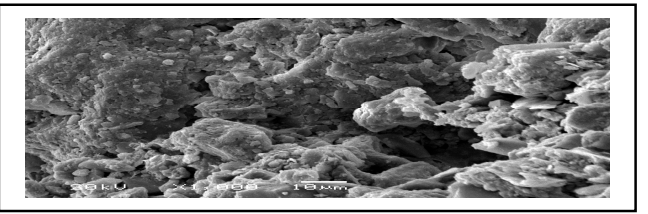

Fig.1 Jingtai loess, 3.3-3.5m

\section{Loessial Micro-structure in the 4-6m}

Post-glacial is the late stage of the last glacial. The Guliya ice core indicates there was a temperature decrease of $11^{\circ} \mathrm{C}$. The post-glacial sedimentary layer is at about 4-6m underground. Fig. 2 of Lintao is shown the granular structure and cementation bracket structure, which can serve as proofs. The micro-structure image of this period shows that the micro-structure is mainly characterized by big sand particles and loosely accumulated weak cementation. The clay cementation around particles and eluviation pedogenesis are quite weak. So in this period, sand sedimentation speed increased and the climate was arid. The micro-structure record witnessed colder period of intense sand sedimentation.

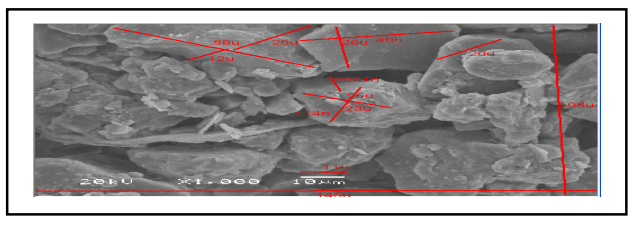

Fig .2 Lintao loess, Gansu, $4 \mathrm{~m}$

\section{Loessial Microstructure in 8m}

It is around $12 \mathrm{kaBP}$ the plateau came into the last deglaciation, the sedimentary layer is at $7-8 \mathrm{~m}$ underground; The micro-structure of this period is in the form of closely-packed granular bracket structure. Particle sizes decrease, while cementation is strengthened, as is shown in Fig.3. The particle size of the loess sample from Xiaguanying decreases to $4011 \mathrm{um}^{3}$ at $8 \mathrm{~m}$, and this indicates a weak wind-blown sand action, increased clay $(<25 \mathrm{um})$ falling number (see Figure 10$)$. It is a warm and humid period.

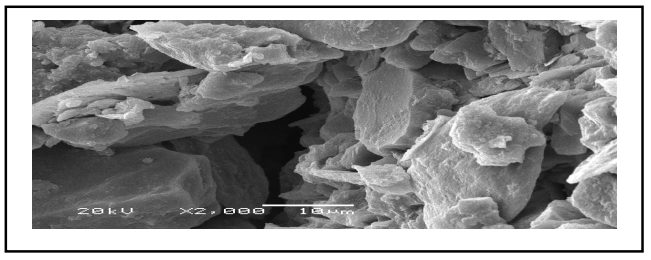

Fig. 3 Lijiawan, Lintao 8m

\section{Microstructure in the $12 \mathrm{~m}$}

The glacial maximum was around 30-15kaB.P, end of the late Pleistocene. The microstructure of this period shows characteristic of weak cementation with closely packed large sand particles. The high proportion of large sand particles and a denser accumulation than the post-glacial should have been resultants of a combination of coldness, strong precipitation and intense wind-blown sand 
actions. Aridity and frequent wind-blown sand actions were characterized by higher sand sedimentation speed and the thickest loess sedimentary layer.

As is shown in Fig.4, it is notable that, in $12 \mathrm{~m}$ sample from Lintao, particle sizes are great and even reach to $15461 \mathrm{um}^{3}$; the sand-dropping speed is the highest among all the periods.

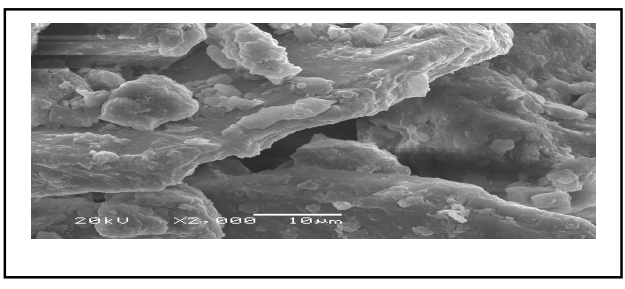

Fig.4 Lijiawan, Lintao, Gansu, 12m

\section{Conclusions}

Based on images and indices of the loess microstructure in the major sedimentary areas of Gansu, China, characteristics of loess formed in different sedimentary ages are compared. The microstructure of loess can also serve as direct proof of climatic changes. For instance, the glacial maximum is characterized by closely-packed large and coarse particles; the glacial minimum by small particles and more clay particles; the post-glacial by large particles and loose, indicating a colder and drier climate than the glacial maximum; and the interglacial by fine particles and more crystalloids, indicating warm and humid climate. It can be found through the microstructure analysis to provide loess engineering properties different.

\section{Acknowledgements}

This work was financially supported by the National Natural Science Foundation of China (No. 51578518).

\section{References}

[1] Liu D.S., Loess and Environment [M]: Beijing Science Press, 1985(1-207).

[2] L.M. Wang, Loess dynamics, Beijing earthquake publishing house, 2005.

[3] Lu, H,Y., An, Z,S., 1998, Paleoclimatic significance of grain size of loess palaeosol deposit in Chinese Loess Plateau: Science in China(Series D), v.28(3).p.278- 283.

[4] Guo Z,T., Soil micromorphology and its appficafion to paleosols: Quaternary Geology and Environment in China. Beijing:China Ocean Prose,1997( 188-194).

[5] Lu H.Y.,Wang X,Y., An Z,S . et a1. 2004,geomorphologie evidence of phased uplift of the Northeastern Qighai-Tibet Plateau since 14 million years ago: Scince in China(Series D), Vol.47(2004).p.822-833.

[6] Chen F,H., Ma Y.Z. and Li J.J. High Resolution Record of Malan Loess in the Longxi Loess Plateau and Rapid Climate Changes during the Last Glaciation: Journal of glaciology and geocryology, Vol.8(1996), p.32-45.

[7] J.DENG,L.M. WANG, Z.Z. ZHANG, H. BING. Microstructure characteristics and forming environment of late Quaternary Period loess in the Loess Plateau of China[J]. Environmental Earth Sciences, Springer Berlin / Heidelberg, ISSN: 1866-6280 (Print),( 2009).p. 1866-6299. 
[8] Deng J., L.M. Wang, Z.Z.Zhang. Microstructure characteristics and seismic subsidence of loess. Chinese Journal of Geotechnical Engineering, 27 (4) .2007,:542-548.)

[9] Deng Jin,WANG Lanmin,,SUN Junjie. The loess Phosphoric modified methods for defending seismic loading subsidence and analysis on its microstructure. Advanced Materials Research, Vols. 838-841(2014),p 1600-1608,.

[10] Deng Jin,WANG LanMmin, BING Hui, Xu Shunhua. The Acid Modification Method to Reduce the Loess Liquefaction Potential. Advanced Materials Research, Vols.1065-1069(2015),pp 219-222,. 